\title{
Differentiation regularity of urban-rural equalized development at prefecture-level city in China
}

\author{
LIU Yansui ${ }^{1,2}$, CHEN Cong ${ }^{1,3}$, LI Yurui ${ }^{1}$ \\ 1. Institute of Geographic Sciences and Natural Resources Research, CAS, Beijing 100101, China; \\ 2. College of Resources Science and Technology, Beijing Normal University, Beijing 100875, China; \\ 3. University of Chinese Academy of Sciences, Beijing 100049, China
}

\begin{abstract}
The urban-rural equalized development (URED) as a definite measure and operating model is beneficial to gradually eliminating the dual-track structure of urban-rural development, bridging the gap of urban-rural development, and creating harmonious urban-rural interactions. This paper aims to explore the status quo of URED in China at prefecture level, and to reveal the spatio-temporal patterns of URED and its differentiation regularity. The results show that: (1) China's URED level can be categorized into two parts, i.e., the eastern and the western, according to the "HU Huanyong Line", presenting a pattern of "east high and west low" and the URED level improves on the whole with the increase of distance from the line; (2) China's URED level can also be categorized into the northern and the southern parts according to "Kunlun-Qinling-Huaihe Line", presenting a pattern of "north high and south low", and the URED level reduces on the whole with the increase of distance from the line; (3) At the national level, China's URED has a significant trend of spatial agglomeration, the high and low URED regions tend to be adjacent, namely, the URED level presents obvious regional unbalance; (4) The five sub-dimension indicators of the URED level in the geographical space also reveal similar regional differentiation pattern, and in the aspect of space a decreasing trend is found in the URED level from the eastern (northern coast, eastern coast and southern coast), the northeastern, the central (the middle reaches of the Yangtze River and the Yellow River) to the western (northwest and southwest); and (5) China's URED at prefecture-level city can be divided into five types of differentiation areas. This study contributes to promoting the integrative cognition of the status quo of China's URED and can serve as a scientific reference concerning the decision-making of coordinating urban-rural development and of pushing forward new-type urbanization strategy in China.
\end{abstract}

Keywords: urban-rural equalized development; urban-rural development transformation; urbanization; rural disease; differentiation regularity; China

\section{Introduction}

After more than three decades of reform and opening up, China has made significant progress in socio-economic development, at the same time, the chain effect caused by long-term

Received: 2015-02-06 Accepted: 2015-04-20

Foundation: National Natural Science Foundation of China, No.41130748, No.41471143

Author: Liu Yansui, PhD and Professor, specialized in land use science and urban-rural development. E-mail: liuys@igsnrr.ac.cn 
deprivation on agriculture and rural areas has become increasingly prominent in the process of rapid industrialization and urbanization (Liu, 2006; Liu et al., 2011; Li and Li, 2012; Liu et al., 2015). The drawbacks of urban-rural division, land partition and man-land separation are increasingly exposed (Liu et al., 2014a), the supplying shortage of education, medical and pension is increasingly exacerbated (Bai et al., 2014), and the "rural disease" due to the rapid urbanization becomes increasingly worsening (Liu, 2013), which comprehensively lead to the difficulty of urban-rural coordinated development and sustainable development of rural economy. Since the Third Plenary Session of 18th CPC Central Committee, China's economy has entered a period of new normal (so called "Xin Changtai" in Chinese), and the changing economic development mode and the transformation of urban-rural development are imperative (Liu et al., 2014b). It is urgent to innovate the theory of cognition and search optimization strategies, which can serve as a theoretical basis regarding decision-making of coordinating urban-rural development in the transitional period of China (Fan and Li, 2009; Long, 2014; Long et al., 2010). In 1988, the Seidel Foundation selected Nanzhanglou village of Shandong Province to promote the urban-rural equalized development (URED) test, which created a China's "Nanzhanglou model". The value of URED is not only to highlight coordinating urban-rural development policy, of which the industry aids the agriculture and the urban supports the rural, but also to embody the general requirements of the beautiful countryside construction, with ecological industry, beautiful environment, wealthy life and civilized local custom. Aiming at meeting the needs of town-village construction and urban-rural integrated development, and focusing on the globality, comprehensiveness and regionality of urban-rural geographical system, studying the URED issue is an objective need in response to transformation in the aspects of regional development theory and the practice of simultaneous urban-rural development. It is also helpful for building a long-term mechanism for rural development, deepening the understanding of the geography of new town and village construction and refining the urban-rural development theory.

Currently, numerous studies have analyzed China's urban-rural development from the multidisciplinary perspectives of geography, economics and sociology. Previous studies mainly focused on the essential characteristics (Chen et al., 2010), spatio-temporal patterns (Bi et al., 2013; Li et al., 2013; Liu et al., 2014b) as well as dynamic mechanism (Liu et al., 2008; Long et al., 2009). However, few studies concentrated on China's urban-rural equalized development. Liu et al. (2013) explored the basic connotation and index system of URED and made a preliminary analysis of the URED differences at provincial scale in China. This paper tries to take the prefectural-level city in China as the research unit to reveal the spatio-temporal patterns of URED and its differentiation regularity, delimit the types of geographical areas of URED, explore the ideas on development and optimization strategy of different regions, and serve as a scientific reference concerning the decision-making of coordinating urban-rural development and of pushing forward new-type urbanization strategy in China.

\section{Evaluation index system and methodology}

\subsection{Methodology}

(1) Measuring the URED. This paper uses comprehensive index evaluation method to 
quantitatively measure the URED level. Based on established index system for assessing urban-rural equalized development, a URED level measurement model has been built using multi-index comprehensive measurement method (Liu et al., 2013). According to the objectives of URED, which are to smoothly accomplish the distinctive equalization of urban-rural spatial location, economic investment, social services, ecological environment and quality of life, this paper selects five target layers of spatial location $\left(B_{1}\right)$, economic investment $\left(B_{2}\right)$, social services $\left(\mathrm{B}_{3}\right)$, ecological environment $\left(\mathrm{B}_{4}\right)$ and life quality $\left(\mathrm{B}_{5}\right)$ and related 16 identified specific indicators, to constitute a comprehensive evaluation system of URED. Due to the changes in the research scale and data availability, this paper modifies some original index, for example, adjusting "average number of university students among ten thousand people" to "average year of education", "ratio of industrial wastewater standards discharge" to "urban household sewage treatment rate", "consumption of chemical fertilizer" to "household waste harmless treatment rate", and "forest coverage" to "greenery coverage" (Table 1). The mathematical expression of the URED level evaluation model is as follows:

$$
A Y=\sum_{i=1}^{n} F_{i} \sum_{n_{i}}^{m_{i}} W_{i j} C_{i j}
$$

where $A Y$ is the index of URED, $n$ is the number of criteria indices, $F_{i}$ is the $i$ th criteria index weight, $W_{i j}$ is the weight of the $j$ th individual index in the $i$ th criteria index, $C_{i j}$ is the value of the $j$ th individual index in $i$ th criteria index and $m_{i}$ is the number of individual indices in the $i$ th criteria index.

At the provincial scale, the author used principal component analysis (PCA) method to determine the weight of each index (Liu et al., 2013). Due to the changes in the research scale and some indices, this paper adopts the expert consultation method (Delphi) for weight calculation. Specifically, 15 experts concerning urban-rural development were invited to determine the relative importance of each index, finally the weight coefficients of indices were obtained (Table 1).

(2) Exploring spatial distribution and classification. 1) The geostatistical analyst method is used to reveal spatial distribution trend of the URED level. Large span space geographical data can be done by trend surface analysis of semi-quantitative research (Dornkamp, 1972). Trend surface analysis can simulate the changes in spatial distribution of geographical elements and trends (Xu, 2002), and it is the approximation of the actual surface. Trend analysis chart of each vertical bar represents a data point value (height) and location. These points are projected onto orthogonal plane at an east-west and a north-south direction, through the projection point to draw the best-fit line, to simulate the changing trend on a particular direction (Liu and Yang, 2012). 2) The spatial autocorrelation analysis method is used to detect the geographical differentiation regularity of URED. Global spatial autocorrelation can describe the cluster status of property values' spatial distribution from the overall of regional space (Anselin, 1996). In general, the global spatial autocorrelation analysis includes Global Moran's I and Geary's C, this paper uses Global Moran's I to reveal the characteristics of spatial data. The positive spatial correlation represents similar eigenvalue in adjacent areas that shows a trend of clusters. 3) By using cluster analysis method to explore the type division of China's URED. System cluster analysis method is widely used in the process of 
Table 1 Assessing index system of the URED level

\begin{tabular}{|c|c|c|c|c|c|}
\hline Target layer & Criterion layer & Index layer & Calculation formula & Weight & Impact \\
\hline \multirow[b]{2}{*}{$\begin{array}{l}\text { Spatial } \\
\text { location }\end{array}$} & Transportation & $\begin{array}{l}\text { Highway net density } \\
\left(\mathrm{x}_{1}\right)\end{array}$ & $\begin{array}{l}\text { Highway mileage }(\mathrm{km}) / \text { Area of land }(100 \\
\left.\mathrm{km}^{2}\right)\end{array}$ & 0.0606 & + \\
\hline & $\begin{array}{l}\text { Spatial distri- } \\
\text { bution }\end{array}$ & $\begin{array}{l}\text { Degree of spatial struc- } \\
\text { ture concentration }\left(\mathrm{x}_{2}\right)\end{array}$ & $\begin{array}{l}P=100-1 / 2 \sum_{i=1}^{n}\left(G_{i}-R_{i}\right) \text { where } P \text { is the } \\
\text { degree of spatial structure concentration; } \\
G_{i} \text { is the ratio of GDP of the } i \text { th region in } \\
\text { total GDP, } R_{i} \text { is the ratio of population of } \\
\text { the } i \text { th region in total population at the } \\
\text { year-end. }\end{array}$ & 0.0449 & + \\
\hline \multirow{5}{*}{$\begin{array}{l}\text { Economic } \\
\text { investment }\end{array}$} & $\begin{array}{l}\text { Economic } \\
\text { development }\end{array}$ & $\begin{array}{l}\text { Per capita gross domes- } \\
\text { tic product }(\mathrm{GDP})\left(\mathrm{x}_{3}\right)\end{array}$ & $\begin{array}{l}\text { Gross Domestic Product } \\
\text { (GDP)/Population at the year-end }\end{array}$ & 0.1023 & + \\
\hline & $\begin{array}{l}\text { Industrial } \\
\text { division of } \\
\text { labor }\end{array}$ & $\begin{array}{l}\text { Proportion of nonfarm } \\
\text { payroll employment }\left(\mathrm{x}_{4}\right)\end{array}$ & $\begin{array}{l}\text { Population of rural nonfarm payroll } \\
\text { employment /Population of rural em- } \\
\text { ployment }\end{array}$ & 0.0457 & + \\
\hline & \multirow{2}{*}{$\begin{array}{l}\text { Financial } \\
\text { investment }\end{array}$} & $\begin{array}{l}\text { Relative proportion of } \\
\text { financial support for } \\
\text { agriculture }\left(\mathrm{x}_{5}\right)\end{array}$ & $\begin{array}{l}\text { Proportion of the financial support for } \\
\text { agriculture in total financial investment/ } \\
\text { Proportion of the primary industry in } \\
\text { GDP }\end{array}$ & 0.0314 & + \\
\hline & & $\begin{array}{l}\text { Ratio of urban-rural } \\
\text { fixed-asset investment } \\
\left(\mathrm{x}_{6}\right)\end{array}$ & $\begin{array}{l}\text { Rural fixed-asset investment /Urban } \\
\text { fixed-asset investment }\end{array}$ & 0.0235 & - \\
\hline & $\begin{array}{l}\text { Production } \\
\text { efficiency }\end{array}$ & $\begin{array}{l}\text { Index of urban-rural } \\
\text { productivity of dual } \\
\text { track structure }\left(\mathrm{x}_{7}\right)\end{array}$ & $\begin{array}{l}Q=\sqrt{(V 1 / E 1) /(V 2 / E 2)} \text { where } Q \text { is the } \\
\text { index of urban-rural productivity of dual } \\
\text { track structure; } V_{1} \text { and } V_{2} \text { are added value } \\
\text { of the primary industry, and added value } \\
\text { of the secondary and tertiary industry, } \\
\text { respectively; } E_{1} \text { and } E_{2} \text { are employed } \\
\text { population of the primary industry, and } \\
\text { employed population of the secondary } \\
\text { and tertiary industry, respectively }\end{array}$ & 0.0632 & + \\
\hline \multirow{2}{*}{$\begin{array}{l}\text { Social } \\
\text { services }\end{array}$} & $\begin{array}{l}\text { Education and } \\
\text { culture }\end{array}$ & $\begin{array}{l}\text { Average year of educa- } \\
\text { tion }\left(\mathrm{x}_{8}\right)\end{array}$ & $\begin{array}{l}\text { Total number of all types of educational } \\
\text { level of schooling /Population at the } \\
\text { year-end }\end{array}$ & 0.1099 & + \\
\hline & Health care & $\begin{array}{l}\text { Average number of } \\
\text { hospital beds per ten } \\
\text { thousand inhabitants }\left(x_{9}\right)\end{array}$ & $\begin{array}{l}\text { Number of hospital beds/Population at } \\
\text { the year-end }\end{array}$ & 0.0643 & + \\
\hline \multirow{3}{*}{$\begin{array}{l}\text { Ecological } \\
\text { environment }\end{array}$} & \multirow{3}{*}{$\begin{array}{l}\text { Ecological } \\
\text { environment }\end{array}$} & $\begin{array}{l}\text { Urban household sew- } \\
\text { age treatment rate }\left(\mathrm{x}_{10}\right)\end{array}$ & $\begin{array}{l}\text { Amount of household sewage discharge } \\
\text { standard/Household sewage discharged }\end{array}$ & 0.0385 & + \\
\hline & & Greenery coverage $\left(\mathrm{x}_{11}\right)$ & $\begin{array}{l}\text { Built-up green areas/Area of administra- } \\
\text { tive units }\end{array}$ & 0.0608 & + \\
\hline & & $\begin{array}{l}\text { Household waste harm- } \\
\text { less treatment rate } \mathrm{x}_{12} \text { ) }\end{array}$ & $\begin{array}{l}\text { Amount of household waste harmless } \\
\text { treatment/Amount of household waste }\end{array}$ & 0.0332 & + \\
\hline \multirow{4}{*}{ Life quality } & \multirow{2}{*}{ Income gap } & $\begin{array}{l}\text { Ratio of urban-rural } \\
\text { residents' income }\left(\mathrm{x}_{13}\right)\end{array}$ & $\begin{array}{l}\text { Per capita net income of rural house- } \\
\text { holds/per capita disposable income of } \\
\text { urban households }\end{array}$ & 0.0875 & - \\
\hline & & Gini coefficient $\left(\mathrm{x}_{14}\right)$ & $\begin{array}{l}G=1.067-20.22(1 / \mathrm{A})-0.89 \operatorname{LnA}, \text { where } G \\
\text { is Gini coefficient; } A \text { represents gross } \\
\text { domestic product }\end{array}$ & 0.1171 & - \\
\hline & \multirow{2}{*}{$\begin{array}{l}\text { Distinction of } \\
\text { consumption }\end{array}$} & $\begin{array}{l}\text { Ratio of urban-rural } \\
\text { residents' Engel coeffi- } \\
\text { cient }\left(\mathrm{x}_{15}\right)\end{array}$ & $\begin{array}{l}\text { Rural residents' food expenses out of the } \\
\text { consumption expenditure/Urban resi- } \\
\text { dents' food expenses out of the consump- } \\
\text { tion expenditure }\end{array}$ & 0.0403 & + \\
\hline & & $\begin{array}{l}\text { Ratio of urban-rural } \\
\text { residents' consumption } \\
\text { expenditure }\left(\mathrm{x}_{16}\right)\end{array}$ & $\begin{array}{l}\text { Rural residents' consumption expendi- } \\
\text { ture/Urban residents' consumption ex- } \\
\text { penditure }\end{array}$ & 0.0768 & - \\
\hline
\end{tabular}


geographical entity's type division among various geological factors, also an important part of rural development sector (Li et al., 2011). This paper adopts the method to classify the types of URED level.

\subsection{Data sources and processing}

This study makes use of data in 2000, 2006 and 2012 for the 344 prefecture-level administrative units in China. The socio-economic data used in this study are mainly extracted from China City Statistical Yearbook, China Regional Economy Statistical Yearbook, China Environmental Statistics and China Statistical Yearbook (in 2001, 2007 and 2013). A few missing data in a certain prefecture has been obtained by data interpolation. The basic geographical information data come from Data Center for Resources and Environmental Sciences, Chinese Academy of Sciences. Due to the different units used in various indices, in order to eliminate the impact of different dimensional data on the comprehensive evaluation, it is necessary to standardize the original data of various indices (Long et al., 2014). By using range standardization method, the study makes linear transformation on original data, which allows the results fall into the section of $[0,1]$. The formula is as follows:

$$
Z= \begin{cases}\left(X-X_{\min }\right) /\left(X_{\max }-X_{\min }\right) & \text { (Positive Index) } \\ \left(X_{\max }-X\right) /\left(X_{\max }-X_{\min }\right) & \text { (Negative Index) }\end{cases}
$$

where $X$ is the value of evaluation index, $X_{\max }$ and $X_{\min }$ mean the maximum and minimum values of the evaluation index, respectively. $Z$ is the value of standardization.

\section{Analysis of the pattern of URED}

This paper selects the phase III data from 2000 to 2012 and uses comprehensive index evaluation method to quantitatively measure the URED level of prefectures in China. In order to reveal the spatial distribution characteristics of URED, this study makes the classification and gradation of the URED level and its five sub-dimension indicators based on the data spatial distribution and "Natural Breaks Jenks" function of ArcGIS. The 344 prefectures can be divided into five types of areas, and the standard of classification and gradation is shown in Table 2. Then, this paper uses the "Trend Analysis Tool" of geostatistical analyst to conduct the three-dimensional visual analysis of the URED's global trends, so as to reveal spatial distribution trend of the URED level, where $\mathrm{X}$ and $\mathrm{Y}$ directions are representing east and north, respectively. Spatial visualization of analysis result is shown in Figures 1 and 2.

Table 2 The dividing standards of the URED level in China

\begin{tabular}{|c|c|c|c|c|c|c|}
\hline Rank & $\begin{array}{c}\text { Range of } \\
\text { URED level }\end{array}$ & $\begin{array}{c}\text { Range of spatial } \\
\text { location level }\end{array}$ & $\begin{array}{c}\text { Range of eco- } \\
\text { nomic investment } \\
\text { level }\end{array}$ & $\begin{array}{c}\text { Range of social } \\
\text { services level }\end{array}$ & $\begin{array}{l}\text { Range of eco- } \\
\text { logical environ- } \\
\text { ment level }\end{array}$ & $\begin{array}{l}\text { Range of life } \\
\text { quality level }\end{array}$ \\
\hline 1 & $\mathrm{D} \leq 0.189$ & $\mathrm{D}_{1} \leqslant 0.067$ & $\mathrm{D}_{2} \leqslant 0.152$ & $\mathrm{D}_{3} \leqslant 0.245$ & $\mathrm{D}_{4} \leqslant 0.280$ & $\mathrm{D}_{5} \leqslant 0.135$ \\
\hline 2 & $0.189<\mathrm{D} \leqslant 0.239$ & $0.067<\mathrm{D}_{1} \leqslant 0.095$ & $0.152<\mathrm{D}_{2} \leqslant 0.202$ & $0.245<\mathrm{D}_{3} \leqslant 0.345$ & $0.280<\mathrm{D}_{4} \leqslant 0.400$ & $0.135<\mathrm{D}_{5} \leqslant 0.190$ \\
\hline 3 & $0.239<\mathrm{D} \leqslant 0.309$ & $0.095<\mathrm{D}_{1} \leqslant 0.140$ & $0.202<\mathrm{D}_{2} \leqslant 0.245$ & $0.345<\mathrm{D}_{3} \leqslant 0.445$ & $0.400<\mathrm{D}_{4} \leqslant 0.580$ & $0.190<\mathrm{D}_{5} \leqslant 0.245$ \\
\hline 4 & $0.309<\mathrm{D} \leqslant 0.359$ & $0.140<\mathrm{D}_{1} \leqslant 0.200$ & $0.245<\mathrm{D}_{2} \leqslant 0.335$ & $0.445<\mathrm{D}_{3} \leqslant 0.545$ & $0.580<\mathrm{D}_{4} \leqslant 0.700$ & $0.245<\mathrm{D}_{5} \leqslant 0.325$ \\
\hline 5 & $\mathrm{D}>0.359$ & $\mathrm{D}_{1}>0.200$ & $\mathrm{D}_{2}>0.335$ & $\mathrm{D}_{3}>0.545$ & $\mathrm{D}_{4}>0.700$ & $\mathrm{D}_{5}>0.325$ \\
\hline
\end{tabular}




\subsection{Overall spatial distribution characteristics of URED}

(1) From the north-south direction, China's URED level can be categorized into the eastern and western parts according to "HU Huanyong Line", a "geo-demographic demarcation line" discovered by Chinese population geographer HU Huanyong in 1935, presenting a pattern of "east high and west low" and the URED level improves on the whole with the increase of distance from the line (Figure 2), presenting a pattern of slightly left tilt line (Figure 1). For example, the URED index of Nagqu of Tibet on the west of "HU Huanyong Line", is $0.112,0.121$ and 0.136 in 2000, 2006 and 2012, respectively, and the URED index of Urumqi of Xinjiang, farthest from Hu's Line, is $0.350,0.379$ and 0.459 , respectively, at the same time, which is the highest in all prefectures on the west of "HU Huanyong Line". Similar phenomenon exists on the east side. Take Bijie of Guizhou Province as an example, its URED index is $0.142,0.162$ and 0.207 in 2000, 2006 and 2012, respectively, which is the lowest on the east of "HU Huanyong Line", and Shanghai, Shenzhen, far from the line, their URED indices are higher.

(2) From the east-west direction, China's URED level can be divided into the northern and southern parts according to "Kunlun- Qinling-Huaihe Line", presenting a pattern of "north high and south low" (Figure 2), and the URED level decreases on the whole with the increase of distance from the line, presenting a pattern of slightly right tilt line, magnitude of inclination is less than the trend line in east-west direction (Figure 1). For example, the

(a) 2000

\section{Z}

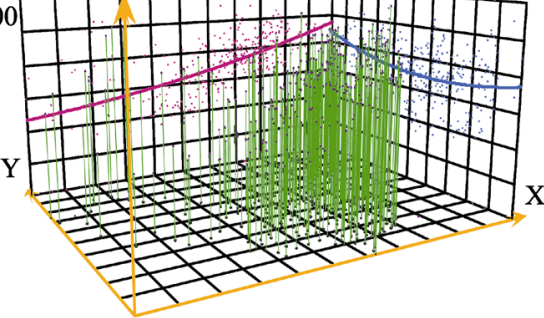

(b) 2006

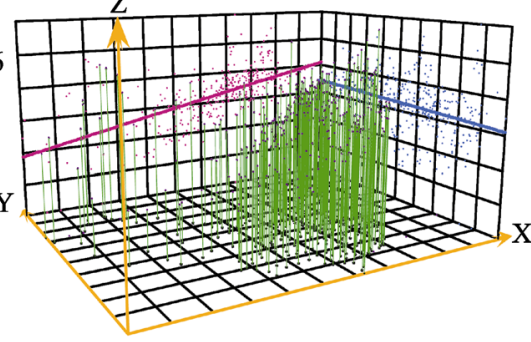

(c) 2012

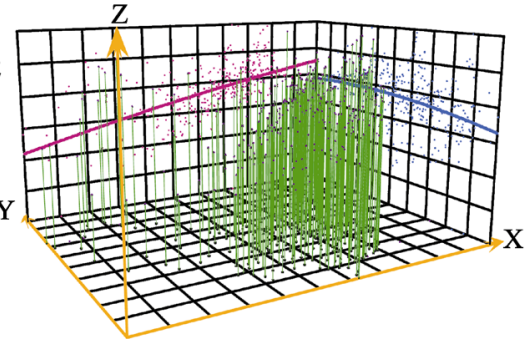

Figure 1 Trends analysis of the URED level in China
URED index of Weihai of Shandong Province on the north of "Kunlun-Qinling-Huaihe Line", is $0.306,0.394$ and 0.454 in 2000, 2006 and 2012, respectively, which is higher on the north side. And the URED index of Qiqihar of Heilongjiang Province farthest from "KunlunQinling-Huaihe Line", is 0.231, 0.241 and 0.297 , respectively, and is the lowest city on the north side. Similar phenomenon also exists on the south of "Kunlun-Qinling-Huaihe Line". Take Shanghai as an example, its URED index is $0.341,0.464$ and 0.522 in 2000, 2006 and 2012, respectively, which is the highest on the south, and Wenshan of Yunnan Province, farther from "Kunlun-Qinling-Huaihe Line", is lower. It is obvious that "scissors type lines" which is formed by the intersection of "HU Huanyong Line" and "Kunlun-Qinling-Huaihe Line" are the important dividing lines reflecting China's URED spatio-temporal patterns.

(3) At the national level, China's URED has a significant trend of spatial agglomeration. The Moran's I indices of China's URED calculated by GeoDA software, are all positive 


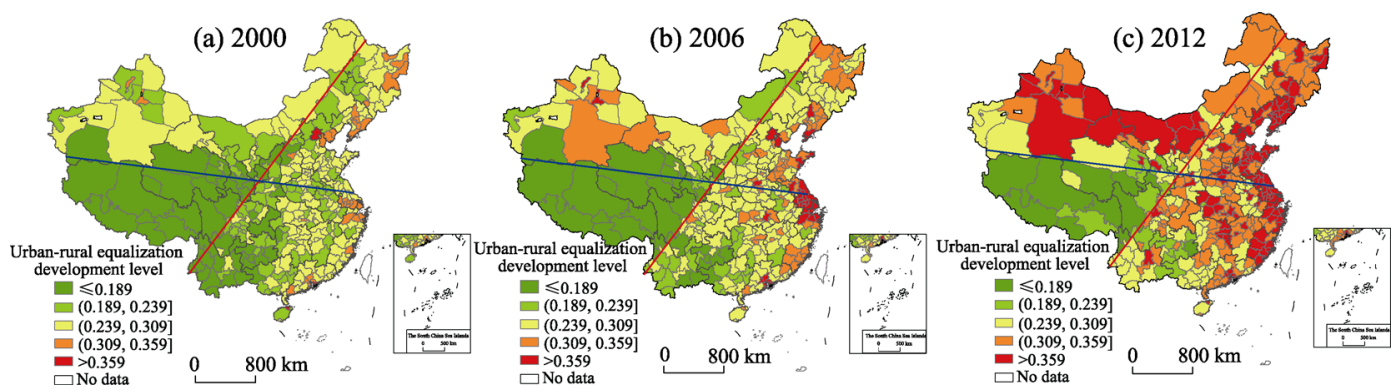

Figure 2 Spatial distribution of the URED level in China

Note: the red line is the "HU Huanyong Line", and the blue line is the "Kunlun-Qinling-Huaihe Line".

in 2000, 2006 and 2012, attaining a significant level of 1\%. And they also have presented a rising trend since 2000, which indicates the spatial interaction between adjacent cities of URED has a tendency to gradually strengthen (Table 3), also means that the similar value of URED has agglomerated in all 344 prefectures since 2000. In other words, the high and low URED regions all tend to be adjacent. Specifically, the URED gap increases among east, central and west of China, and in space a regular character is found in the URED level from the eastern (northern coast, eastern coast and southern coast), the north-eastern, the central (the middle reaches of the Yangtze River and Yellow River) to the western (northwest and southwest).

Table 3 The Global Autocorrelation Moran' I index of URED in China

\begin{tabular}{cccc}
\hline & Moran's I index & Z-score & P-value \\
\hline 2000 & 0.0927 & 12.3267 & 0.0000 \\
2006 & 0.1112 & 14.5688 & 0.0000 \\
2012 & 0.1214 & 15.7564 & 0.0000 \\
\hline
\end{tabular}

\subsection{Spatial distribution characteristics of sub-dimension indicators}

The five sub-dimension indicators of the URED level in the geographical space also reveal similar regional differentiation pattern, and in space a regular decreasing trend is found in the URED level from the eastern (northern coast, eastern coast and southern coast), the north-eastern, the central (the middle reaches of the Yangtze River and Yellow River) to the western (northwest and southwest) (Figure 3).

(1) Spatial location development level. This index has obvious regional differentiation characteristics. There is a significant difference between the two sides of "HU Huanyong Line", and spatial agglomeration pattern has been shaped and increasing. In 2000, regions with low spatial location development level were mainly distributed in northeast, southeast and northwest with the mountains and hills as the dominant topography, thus imposing limits on the development space for cities. The high-level regions were small amount of capital cities and coastal cities featured by spot distribution. Most of the cities boasted excellent traffic conditions and strong economic strength. In 2006, the overall level of the index for all prefectures increased significantly, and the pattern of "east high and west low" had been strengthened. The high-level regions were of contiguous distribution representing an 
(a) 2000

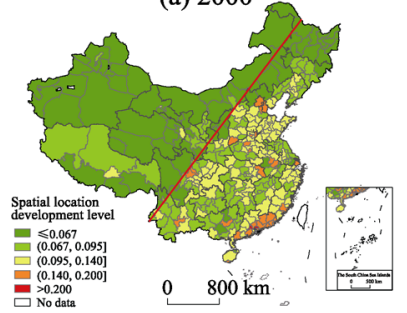

(d) 2000

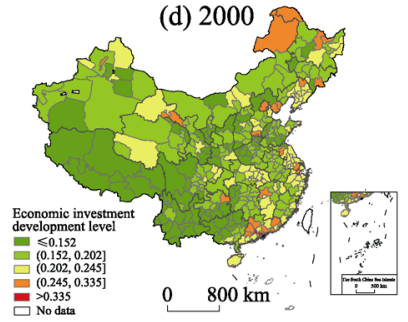

(g) 2000

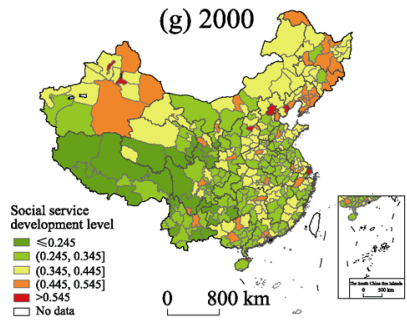

(j) 2000

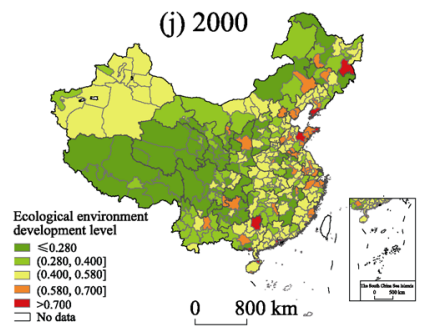

(m) 2000

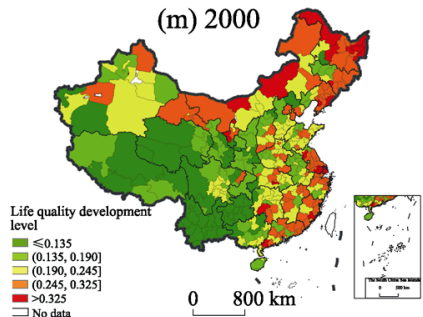

(b) 2006

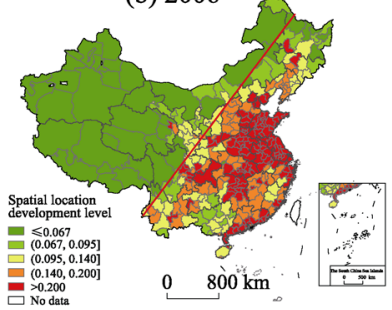

(e) 2006

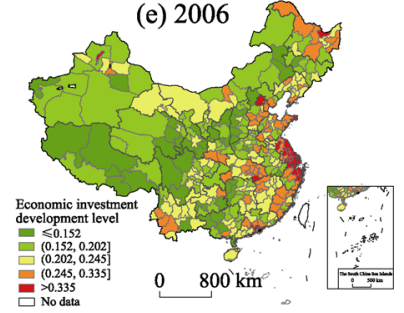

(h) 2006

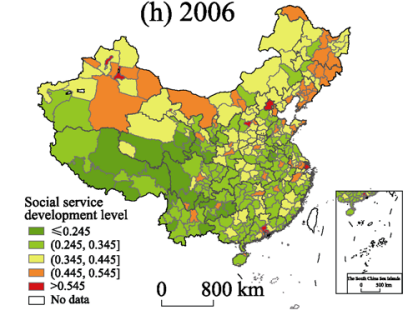

(k) 2006

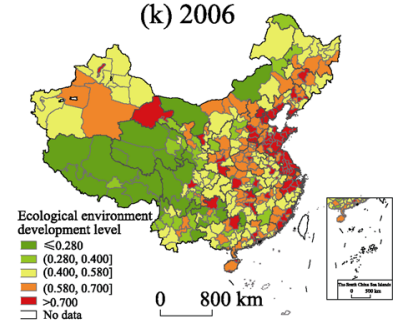

(n) 2006

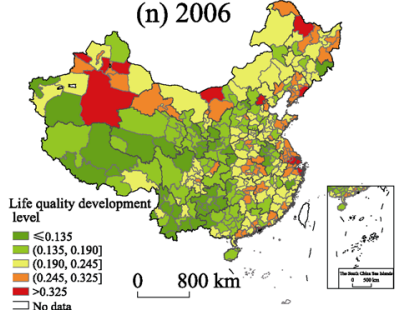

(c) 2012

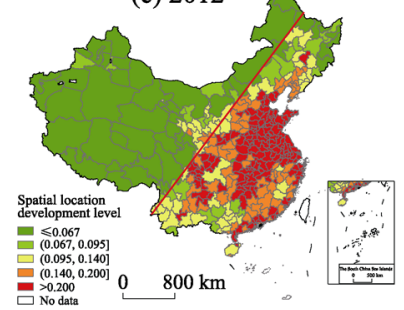

(f) 2012

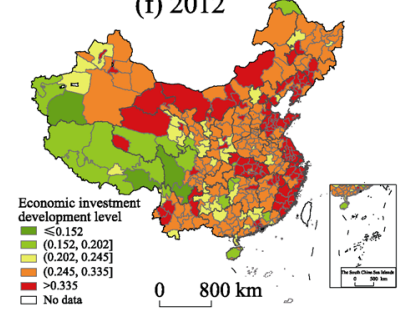

(i) 2012

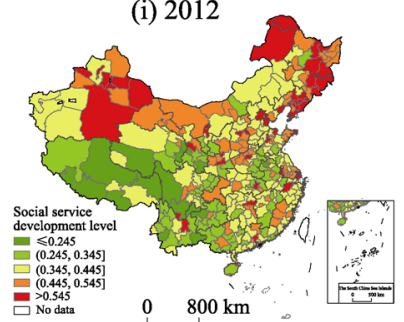

(1) 2012

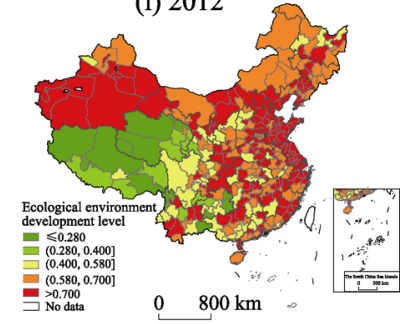

(o) 2012

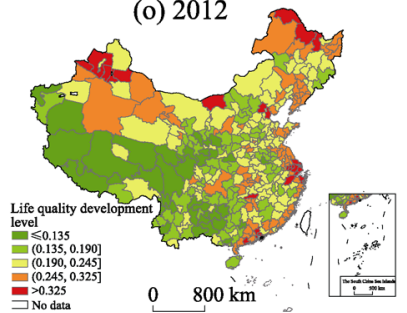

Figure 3 Spatial distribution of sub-dimension indicators of the URED level in China

agglomeration pattern, mainly in eastern coastal region, Chengdu-Chongqing region and the middle reaches of the Yangtze River. However, the spatial development level was still low and grew slowly in northeast, southwest and northwest regions. In 2012, the overall level for all prefectures further increased, and the spatial distribution pattern had seldom changed, still maintaining the "east high and west low" rule. The low-level regions were mainly located in plateau, hilly areas and river valleys while the high-level regions in 
Huang-Huai-Hai Plain, Chengdu Plain and the Yangtze Plain. In general, physical background (especially topography) had a strong effect on spatial location development.

(2) Economic investment development level. In 2000, the number of regions with high level index was small with those scattered in northeast and east coastal regions. However, the majority of the western regions were basically at a low level. Generally, the whole level of all prefectures in economic investment was low, and there were relatively tiny differences among regions. During 2000 to 2006, the national level of economic investment on the whole had significantly increased. There appeared agglomeration in eastern coastal region with high level in regard to the index, for which the regions in the middle reaches of the Yangtze River and the Yellow River increased fast in the same period. By the contrast, most of the regions nationwide were still at a low level. During 2006 to 2012, the national level increased substantially on the whole, and high-level regions had formed various agglomeration areas, mainly in eastern coastal areas, northwest and the middle reaches of the Yangtze River. The phenomenon that high-level regions coincided with the main urban agglomerations in China, including Beijing-Tianjin-Hebei, the Yangtze River Delta and Pearl River Delta and others as such, illustrating the economic investment high-level distribution had certain correlation to urban agglomeration layout. On the contrary, there were fewer regions with low level, which were mainly distributed in the Qinghai-Tibet Plateau.

(3) Social service development level. In 2000, the overall national level of the index was very low and only a few cities were at a high level, such as Beijing, Shanghai, and Haikou. Most of the regions nationwide were at a low level. Compared with 2000, the overall level and spatial distribution pattern were similar to that of 2006. The number of regions with high level increased slightly, and the regions were distributed in Xinjiang, northeast as well as central and eastern regions. During 2006 to 2012, the whole level of this index increased rapidly, and the ranges of high level cities extended and showed an agglomeration pattern. It illustrated that social service including infrastructure, education and medical care had improved significantly during this period, especially in rural areas. In the same period, southwest such as Tibet, Guizhou and Sichuan Provinces, where physical and geographical conditions were harsh, were also at a low level and the gap between the high level regions becoming wider.

(4) Ecological environment development level. In 2000, almost all prefectures in China were at a low level of this index. There were fewer high-level prefectures, and they were mainly distributed in the eastern region. On the contrary, prefectures in the western region were almost at a low level, especially in southwest regions. During 2000 to 2006, the overall level of the index increased significantly. The eastern coastal area and Pearl River Delta became high-level agglomeration regions. Besides, the other high-level prefectures were scattered with small amount. On the contrary, prefectures with low level of this index were mainly distributed in southwest and Inner Mongolia regions. However, the number of medium-level prefectures was the largest, and they were also the dominant type in the period. In 2012, the overall level increased by a wide margin, and the range of high-level regions gradually extended. There were agglomeration areas in northeast, eastern coastal area and the middle reaches of the Yangtze River. However, low-level regions decreased, which were mainly distributed in Tibet, Qinghai and Sichuan Provinces.

(5) Life quality development level. In 2000, the national level of this index on the whole 
was low, and the gap among different regions was small. Spatially, southwest China is the low value region, the high value regions were scattered and only several prefectures, such as Shenzhen, Suzhou and Wuxi. Compared with 2000, the whole URED level in 2006 decreased instead, this trend was possibly caused by continuously widened income and expenditure gap between urban and rural areas. During 2006 to 2012, the overall national level of this index increased slightly, and high level regions were not that many and mainly distributed in the Beijing-Tianjin-Tangshan region, Yangtze River Delta and Pearl River Delta regions. Low-level regions were further reducing and mainly distributed in western China, with almost all prefectures still at a medium level of this index.

\section{Classification and optimization strategies of URED}

In order to reveal the geographical differentiation law of URED in-depth, and serve as a scientific reference concerning the decision-making of coordinating urban-rural develop-

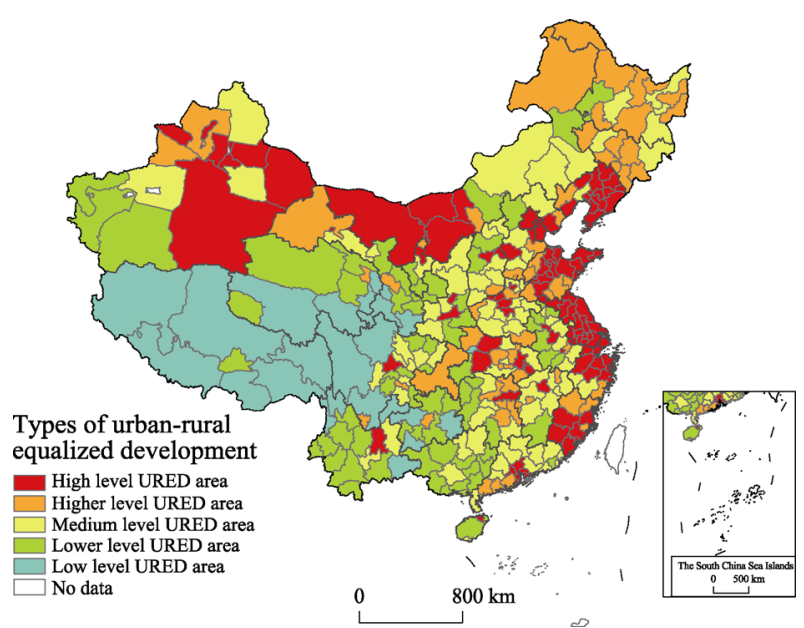

Figure 4 Regional differentiation types of the URED level in China ment and of pushing forward new-type urbanization strategy in China based on the evaluation results in 2012, the 344 prefectures were divided into five types of areas using system cluster analysis method. Besides, taking ArcGIS software as a technology platform, the regional pattern map of types of the URED level was obtained (Figure 4). Then, different optimized strategies for each type were put forward so as to meet the needs of urban-rural integrated development and the requirements of regional meticulous management.

(1) High level URED area. This type includes 99 prefectures and occupies $18.31 \%$ of all prefectures. In 2012, the median of the URED index of this type was 0.4049 , and the mean was 0.4151 . This type was mainly distributed in the Bohai Rim, the Yangtze River Delta, the Pearl River Delta and the area on the northern slope of Tianshan Mountains. This area had better traffic conditions, mature urban development, well-developed infrastructure, perfect social services, high-quality life and the balanced urban-rural development. And it was the most vigorous growth pole with the greatest potential in China. However, some problems existed in this area, evidenced by the worsening aging population, ecological environmental problems, and the gap widening between urban and rural areas. Currently, it is essential to explore the dynamic mechanism of industrial transformation, and to optimize the industrial structure and its spatial layout. Besides, it is essential to improve the ecological environmental quality by strengthening environmental monitoring and management, establishing mechanism for regional environmental coordination and compensation. Meanwhile, we need to refine the infrastructure and social services, establish the aging population security system and support sanatoria industrial development of towns and villages, promote the integration of urban-rural social services effectively. More importantly, it is necessary to speed up the 
reformation and development in rural areas, stimulate rural vitality of entrepreneurship and innovation, and promote on-site urbanization, the industrial park establishment nearby the villages and the diversity of development models, finally narrowing the development gap between urban and rural areas.

(2) Higher level URED area. This type includes 63 prefectures and occupies $18.31 \%$ of all prefectures. In 2012, the median of the URED index of this type was 0.3573 and the mean 0.3573 . This type of area had a relatively high value of URED and was mainly distributed in northern Heilongjiang, western Jilin, northern Gansu, northern Fujian, eastern Hunan, southern Hebei and western Shandong and etc. This type of area was lack of core city, the urban driving and radiation effects were relatively weak, the industrial core competitiveness was not sufficient and the ability to provide social public resources was also limited. Meanwhile, the industrial structure was unreasonable with the relatively large proportion of traditional industrial sectors and strong restriction by resources and environment and the unsustainable economic development. Therefore, it is vital to speed up the upgrading of industrial transformation, enhance the competitiveness of traditional industry, foster new-type technology-intensive industries and explore a new mode of industry-environment cooperative coupling in the future. Meanwhile, it is necessary to strengthen the construction of regional core cities and make them play a leading role in the transformation of rural development, promote the equal allocation of public resources between urban and rural areas, integrate the infrastructure construction, lead the rural production and lifestyle to become modernized, and gradually achieve the urban-rural equalization and rural ecological civilization.

(3) Medium level URED area. This type includes 88 prefectures and occupies $25.58 \%$ of all prefectures. In 2012, the median of URED index of this type was 0.3214 , and the mean was 0.3238, mainly distributed in Songnen Plain, Huang-Huai-Hai Plain, Chengdu Plain, Guanzhong Plain and the middle-lower Yangtze Plain. This type was the core area of grain production in China with flat terrain, fertile soil and abundant arable land. However, the industry of this area was dominated by agriculture with the secondary and tertiary industries less developed. Public service resources were scarce and the overall socio-economic development level was relatively low. Currently, it is urgently needed to stabilize the economic foundation, and enhance self-development capacity and competitiveness. On the one hand, the agricultural subsidy policy should be adjusted in this type of area. To train new types of agricultural talents and protect high-quality cultivated land with strict measures, transform traditional agriculture continuously, and promote the modern high-efficiency agriculture to ensure the national food security. On the other land, it's necessary to scientifically carry out the campaign to consolidate the hollowed villages, refine the withdrawal mechanism of rural housing land, strengthen the guidance of rural construction planning, accelerate the construction of rural communities, intensify the rural environmental governance and optimize the system and pattern of town and village construction. Last but not least, take into account the characteristics of the area and its agricultural conditions, establish public service ration system, strengthen the social insurance system, refine the social service, and practically safeguard and improve the people's livelihoods.

(4) Lower level URED area. This type includes 70 prefectures and occupies $20.35 \%$ of all prefectures. In 2012, the median of the URED index of this type was 0.2768 and the mean 0.2706, which mainly distributed in northern Hebei, southern Ningxia, northern Qinghai, 
Yunnan-Guizhou and Guangxi mountainous and hilly areas. There were many mountains and hills in this region, thus the physical conditions were unfavorable with complex terrain, relief soil, scattered thin-layer cultivated land. As for the social conditions, it had inconvenient traffic, poor medical and education conditions and insufficient social service. Considering its ecological vulnerability, its urban and rural coordinated development requires to enhance the quality of ecological environment in the first place and constantly strengthen the protection of environment. Combining with the characteristics of "large scattered, small clusters" of local population distribution, the space and the platform of URED should be created. Give full play to the supporting services and market radiation effects of central towns and communities, promote public service distribution with appropriate scale and of relative concentration. At last, rely on the unique advantages of light and heat resources to develop mountainous agriculture. Meanwhile, formulate policies to support the featured agriculture, introduce the technical equipment and talents, and improve the processing of agricultural products in order to expand the income channels for farmers.

(5) Low level URED area. This type includes 24 prefectures and occupies $6.98 \%$ of all prefectures. In 2012, the median of URED index of this type was 0.1876 , and the mean was 0.1823. It mainly distributed in Qinghai-Tibet Plateau. This area had many plateaus and mountains with average high altitude, excessive topographical relief, lower temperature, less rainfall and depleted soils. Besides, this area was a sparsely-populated area with the infrastructure seriously lagging behind and poor conditions of the communication and transportation and the insufficiency in the social public services and the quite low level of socio-economic development. As an important global eco-conserving area, the development of this type should follow the principle of integrating the ecological conservation into the economic development. Firstly, make vigorous efforts to develop the plateau characteristic modern agriculture and animal husbandry, constantly deepen the processing level of the related products, improve the added value and the overall production capacity of agriculture, and promote the agricultural transformation to bear higher level of industrialization, organization and ecologicalization. Secondly, regarding to the local physical conditions and the bearing capacity of resources and environment, gradually promote people's mobility out of the unlivable regions. Put forward the policy of ecological immigration step by step, establish and enhance the ecological compensation mechanism and continuously improve the living environment. At last, strengthen the regional communication with the external areas, speed up the development of infrastructure and public service infrastructure, foster and promote the tourism industry focusing on the national features with its integration with the natural landscape. Continuous efforts should be made to expand the income sources, further enhancing the level of income and the quality of life.

\section{Conclusions and discussion}

At present, China has entered a new phase of urban-rural development transformation, three stages of which are urban-rural coordination, urban-rural integration, and urban-rural equalization. Specifically, coordination is the conception, integration is the process, and equalization is the destination. Analysis of the regional differences of URED is the scientific reference concerning the decision-making in strategic planning of coordinating urban-rural 
development, and the cognition of its regulations of regional differentiation will directly affect the direction and its strength of national macroeconomic policy. Based on previous studies (Liu et al., 2013), this paper takes prefecture-level city as the study unit, through concrete evaluation index system and quantitative analysis method, reveal the spatio-temporal patterns of URED and its differentiation regularity in depth, delimit the types of geographical areas of URED, and explore the ideas on development and optimization strategy of different regions.

(1) There were significant spatial differences in the URED level, which were divided into east and west, north and south sides largely based on "HU Huanyong Line" and "Kunlun-Qinling-Huaihe Line". The URED level presented a pattern of "east high and west low", "north high and south low", and the URED level improved on the whole with the increase of distance from "HU Huanyong Line, but decreased on the whole with the increase of distance from "Kunlun-Qinling-Huaihe Line". Besides, at the national level, China's URED had a significant trend of spatial agglomeration, the high and low URED regions tended to be adjacent, the URED level presented a high regional unbalance. The five sub-dimension indicators of the URED level in the geographical space also revealed some regional differentiation patterns, and in space a regular decreasing trend was found in the URED level from the eastern (northern coast, eastern coast and southern coast), the northeastern, the central (the middle reaches of Yangtze River and Yellow River) to the western (northwest and southwest).

(2) Based on the evaluation results, China's URED level was divided into five regional types, i.e., high level URED area, higher level URED area, medium level URED area, lower level URED area and low level URED area. The urban-rural equalized development was attributable to the influences of physical conditions, the economic development level, together with the national policies and institution. There were significant differences in dominant influencing factors of different types of regions. Therefore, it is better to explore different ideas on development and optimization strategies, promote the macroscopic regulation, urban-rural coordinated governance, town-village self-management, strengthen the strategy's pertinence and emphasize the differences of the policy continuously in order to accommodate the needs of urban-rural integrated development and requirements of regional meticulous management.

(3) This paper discussed the spatio-temporal patterns and spatial differentiation of China's URED in depth. However, the connotation of URED is more systematic and plentiful than what was reflected by the current index system. Due to limited data sources, it is difficult to systematically analyze the urban-rural spatial location, ecological environment and social services at county level, so the microscopic pattern of URED remains to be explored in depth, especially many Chinese cities face a number of air pollution and social inequity problems with the rapid urbanization and urban transformation, so it is needed to deeply study the equivalence of urban and rural environmental quality and the resident livelihood level. This paper used system cluster analysis method to classify the types of China's URED and put forward various optimized strategies for different types, but the dominant driving factors, microscopic dynamic mechanism and geographical mode still need to be explored in the future. 


\section{References}

Anselin L, 1996. The Moran scatter plot as an ESDA tool to assess local instability in spatial association. In: Fisher M, Scholten H J, Unwin D. Spatial Analytical Perspectives on GIS. London: Taylor \& Francis.

Bai Xuemei, Shi Peijun, Liu Yansui, 2014. Realizing China's urban dream. Nature, 509(1799): 158-160.

Bi Yuzhu, Gou Tianlai, Zhang Qianzhi et al., 2012. The urban-rural equalized development mode and its enlightenment in German: For example in Bavaria. Ecological Economy, (5): 99-102. (in Chinese)

Chen Yiu Por, Liu Mingxing, Zhang Qi, 2010. Development of financial intermediation and the dynamics of urban-rural disparity in China, 1978-1998. Regional Studies, 44(9): 1171-1187.

Dornkamp J C, 1972. Spatial Analysis in Geomorphology. Harper \& Row Publishers.

Fan Jie, Li Pingxing, 2009. The scientific foundation of Major Function Oriented Zoning in China. Journal of Geographical Sciences, 19(5): 515-531.

Li Jiuyi, Li Lijuan, 2012. Water resources supporting capacity to regional socio-economic development of China. Acta Geographica Sinica, 67(3): 410 - 419. (in Chinese)

Li Yuheng, Zhang Zhenghe, Liu Yansui, 2013. Spatial-temporal contrasts in integrated urban-rural development in China, 1990-2010. China: An International Journal, 11(3): 1-19.

Li Yurui, Liu Yansui, Long Hualou, 2011. Study on the pattern and types of rural development in the Huang-Huai-Hai region. Geographical Research, 30(9): 1637-1647. (in Chinese)

Liu Hui, 2006. Changing regional rural inequality in China 1980-2002. Area, 38(4): 377-389.

Liu Tao, Qi Yuanjing, Cao Guangzhong et al., 2015. Spatial patterns, driving forces, and urbanization effects of China's internal migration: County-level analysis based on the 2000 and 2010 censuses. Journal of Geographical Sciences, 25(2): 236-256.

Liu Yansui, 2013. New-type urbanization should cure "rural disease". The People's Daily, 2013-09-10(A05).

Liu Yansui, Chen Cong, Li Yuheng, 2014a. The town-villages construction pattern under new-type urbanization in China. Areal Research and Devlopment, 33(6): 1-6. (in Chinese)

Liu Yansui, Chen Yangfen, Long Hualou, 2011. Regional diversity of peasant household response to new countryside construction based on field survey in eastern coastal China. Journal of Geographical Sciences, 21(5): 869-881.

Liu Yansui, Hu Zhichao, Li Yuheng, 2014b. Process and cause of urban-rural development transformation in the Bohai Rim Region, China. Journal of Geographical Sciences, 24(6): 1147-1160.

Liu Yansui, Lu Shasha, Chen Yufu, 2013. Spatio-temporal change of urban-rural equalized development patterns in China and its driving factors. Journal of Rural Studies, 32: 320-330.

Liu Yansui, Wang Lijuan, Long Hualou, 2008. Spatio-temporal analysis of land-use conversion in the eastern coastal China during 1996-2005. Journal of Geographical Sciences, 18(3): 274-282.

Liu Yansui, Yang Ren, 2012. The spatial characteristics and formation mechanism of the county urbanization in China. Acta Geographica Sinica, 67(8): 1011-1020. (in Chinese)

Long Dongping, Li Tongsheng, Miao Yuanyuan et al., 2014. The spatial distribution and types of the development level of Chinese agricultural modernization. Acta Geographica Sinica, 69(2): 213-226. (in Chinese)

Long Hualou, 2014. Land use policy in China: Introduction. Land Use Policy, 40: 1-5.

Long Hualou, Liu Yansui, Li Xiubin et al., 2010. Building new countryside in China: A geographical perspective. Land Use Policy, 27(2): 457-470.

Long Hualou, Zou Jian, Liu Yansui, 2009. Differentiation of rural development driven by industrialization and urbanization in eastern coastal China. Habitat International, 33: 454-462.

Xu Jianhua, 2002. Mathematical Methods in Contemporary Geography. Beijing: Higher Education Press. (in Chinese) 